\title{
Niraparib exhibits a synergistic anti-tumor effect with PD-L1 blockade by inducing an immune response in ovarian cancer
}

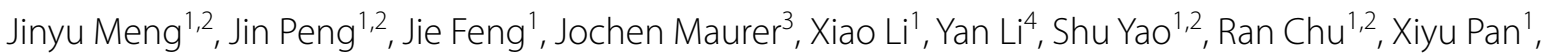
Junting $\mathrm{Li}^{1}$, Ting Zhang ${ }^{2,5}$, Lu Liu' ${ }^{1,2}$, Qing Zhang ${ }^{1,2}$, Zeng Yuan ${ }^{1}$, Hualei Bu${ }^{1}$, Kun Song ${ }^{1,2^{*}}$ and Beihua Kong ${ }^{1,2}$

\begin{abstract}
Background: Immune checkpoint blockades (ICBS) therapy showed limited efficacy in ovarian cancer management. Increasing evidence indicated that conventional and targeted therapies could affect tumor-associated immune responses and increase the effectiveness of immunotherapy. However, the effects of Niraparib, one of the poly (ADP) ribose polymerase (PARP) inhibitors, on the immune response remains unclear. Delineating the crosstalk between cytotoxic anticancer agents and cancer-associated immunity may lead to more efficient combinatorial strategies.
\end{abstract}

Methods: Programmed death ligand 1 (PD-L1) expression in human ovarian cancer cells after PARP inhibitors treatment was examined by western blotting (WB) and flow cytometry. The expression of poly ADP-ribose polymerase (PARP1), PD-L1, and CD8 in human ovarian cancer tissues was detected by immunohistochemistry(IHC). The effect of Niraparib and PD-L1 blockade in ovarian cancer progression was investigated in vivo. The changes of immune cells and cytokines in vitro and in vivo were detected by flow cytometry and enzyme-linked immunosorbent assay (ELISA). Changes of cGAS/STING signal pathway after Niraparib treatment were determined by WB, ELISA.

Results: Niraparib upregulated membrane PD-L1 and total PD-L1 expression in ovarian cancer cells and had a synergistic effect with PD-L1 blockade in vivo. In clinical patient samples, Niraparib augmented cytotoxic CD8 ${ }^{+} T$ cell proportion and function. In vivo and vitro, Niraparib can also increase the proportion of T cells and combined with PD-L1 blockade could further enhance the effect. Besides, Niraparib activated the CGAS-STING pathway, increasing the levels of cytokines such as CCL5 and CXCL10, which played a vital role in augmenting the infiltration and activation of cytotoxic T cells.

Conclusions: Niraparib could modulate the immune response via the activation of the cGAS/STING pathway, and combination with PD-L1 blockade could further enhance the effect. These results provide a sound theoretical basis for clinical treatment.

Keywords: Ovarian cancer, Niraparib, PARP inhibitors, PD-L1, CGAS/STING pathway

*Correspondence: songkun2001226@sdu.edu.cn

1 Department of Obstetrics and Gynecology, Qilu Hospital, Cheeloo

College of Medicine, Shandong University, 107 Wenhua Xi Road, Jinan, Shandong, China

Full list of author information is available at the end of the article

\section{Background}

Ovarian cancer is the most lethal gynecological malignancy and the 5-year survival rate is below 48\% [1], which can be attributed to its insidious nature, difficulties in early diagnosis, and chemotherapy resistance $[2,3]$. In the United States, about 21,750 cases were confirmed and there were 13,940 deaths in 2020 
[4]. Therefore, novel or combined strategies for ovarian cancer other than conventional chemotherapy are urgently needed [5].

Drugs targeting the DNA damage response (DDR) pathway such as Olaparib and Niraparib have been utilized for ovarian cancer therapy. Olaparib was first approved for the treatment of germline $B R C A$ -mutated, platinum-sensitive, recurrent, and highgrade serous ovarian cancer [6]. Niraparib was recently approved by the United States Food and Drug Administration (FDA) for treating patients with recurrent, platinum-sensitive ovarian cancer after at least two previous chemotherapy treatments [7]. Despite the profound and sustained anti-tumor responses observed in treating ovarian cancer patients, resistance to PARP inhibitors has emerged in some cases [8]. To overcome this resistance, it is necessary to explore combinations with other agents, such as immunotherapies.

Although immune checkpoint inhibitors are promising, the response to these agents is limited and increasing evidence has shown primary and adaptive resistance [9]. It has been shown that responses to these agents are related to the mutagenic burden, such as in tumors with $B R C A$ and other homologous recombination (HR) proteins deficiencies [10]. Moreover, PARP inhibitors have been reported to manifest synergistic effects with programmed cell death 1 ligand 1 (PD-L1) blockade in pre-clinical models and clinical trials [11]. However, the interactions between PARP inhibitors and the immune system as well as the underlying molecular mechanisms, remain unknown.

In our study, we investigated the dynamic changes and responses of immune cells and cytokines during Niraparib treatment. Our results showed that Niraparib could upregulate PD-L1 expression, but did not impair the function of immune cells, especially $\mathrm{CD} 8^{+} \mathrm{T}$ cells. Interestingly, Niraparib enhanced the proportion and function of $\mathrm{T}$ cells via activation of the innate immune response pathway. Combined PD-L1 blockade could further promote the recruitment and activation of $T$ cells. Our findings demonstrated that Niraparib exhibited a synergistic effect with immune checkpoint blockade (ICBs) in ovarian cancer therapy, which could shed light on ovarian cancer therapeutic management.

\section{Methods and materials \\ Cell culture}

Human epithelial ovarian cancer cell line UWB1.289

(BRCA1-null) was purchased from the American Type

Culture Collection (ATCC). The SKOV3 and ID8 (murine ovarian carcinoma) cells were obtained from the Chinese Academy of Sciences (Shanghai, China). The SKOV3, ID8, and UWB1.289 cells were cultured in RPMI 1640 medium (GIBCO) with 10\% fetal bovine serum (FBS), $100 \mathrm{U} / \mathrm{ml}$ penicillin, and $100 \mu \mathrm{g} / \mathrm{ml}$ streptomycin. All cells were maintained at $37^{\circ} \mathrm{C}$ with $5 \% \mathrm{CO}_{2}$ in a humidified incubator. PARP1 siRNA1, siRNA2, siRNA3 (siPARP1, Table 1) were purchased from GenePharma (Jiangsu, China). SKOV3 and UWB1.289 cells were transfected with siRNAs using Lipofectamine 2000 (Invitrogen, CA) according to the manufacture's instructions, PARP1 and PD-L1 protein levels were determined by western blotting and flow cytometry.

\section{Chemical inhibitors and antibodies}

Olaparib (PARP inhibitor) was purchased from Selleck (TX, USA). Niraparib was kindly provided by ZaiLab (Shanghai, China). Niraparib was dissolved in dimethyl sulfoxide (DMSO) at a $10 \mathrm{mM}$ concentration for the stock solution and diluted with culture medium to obtain a final DMSO concentration of no more than $0.1 \%$. The antibody anti-human PD-L1 (SHR-1316) was kindly provided by Hengrui (Jiangsu, China). The blocking antibody anti-mouse PD-L1 (Rabbit mAb\#10F.9G2) was purchased from Biolegend (San Diego, CA, USA). STING inhibitor (H-151) was purchased from Selleck (TX, USA).

\section{Patients and tissue samples}

Seventy-two high-grade serous ovarian cancer (HGSOC) formalin-fixed, paraffin-embedded (FTPE) samples were collected from the pathology department and the clinical data were collected from the follow-up center of Qilu Hospital of Shandong University. The study was approved by the Ethics Committee

Table 1 The sequence of PARP1 siRNA

\begin{tabular}{lll}
\hline No & Sequence & Sequence \\
\hline PARP1-homo-2003 & GAGCACUUCAUGAAAUUAUTT & AUAAUUUCAUGAAGUGCUCTT \\
PARP1-homo-1706 & GAGGAAGGUAUCAACAAAUTT & AUUUGUUGAUACCUUCCUCTT \\
PARP1-homo-2699 & GCGAAUGCCAGCGUUACAATT & UUGUAACGCUGGCAUUCGCTT \\
\hline
\end{tabular}


of Qilu Hospital of Shandong University (Approval number: KYLL-2020-138).

\section{Syngeneic model}

The previously cultured ID8 cells were resuspended in $100 \mu \mathrm{l}$ of phosphate-buffered saline (PBS) at a volume of $1 \times 10^{7}$ cells and injected subcutaneously into the right flank of female C57BL/6 mice aged 4-6 weeks were from Vitalriver (Beijing, China). After 2 weeks, the mice were randomized to four groups $(\mathrm{n}=5$ per group): control group, Niraparib $(25 \mathrm{mg} / \mathrm{kg})$ group, PD-L1 blockade group $(10 \mathrm{mg} / \mathrm{kg})$, and Niraparib $(25 \mathrm{mg} / \mathrm{kg})$ with PD-L1 $(10 \mathrm{mg} / \mathrm{kg})$ blockade group. Treatment was started when the tumors formed after two weeks of injection. A dose of $25 \mathrm{mg} / \mathrm{kg}$ Niraparib was administered to the mice orally 4 times per week, and PD-L1 blockade was injected intraperitoneally twice a week. Weight and tumor volume were measured every three days after treatment. The tumor volume was calculated as follows: $\mathrm{V}=\mathrm{a}^{*} \mathrm{~b}^{2} / 2(\mathrm{~V}=$ volume, $a=$ largest diameter of tumor, $b=$ smallest diameter of tumor). The mice were sacrificed 8 weeks after the injection, and tumors were separated and weighed. Part of the tumor was used for the WB assay, and the rest was fixed with $4 \%$ paraformaldehyde for immunohistochemistry. The animal experiments were approved by the Experimental Animal Ethics
Committee of Shandong University (Approval number: 20072).

\section{Immunohistochemistry assay}

Fresh tissue from tumor xenografts was fixed with $4 \%$ paraformaldehyde for $24 \mathrm{~h}$, dehydrated, and embedded in paraffin and immunohistochemical analysis was conducted on paraffin-embedded tumor tissue sections $(5 \mu \mathrm{m})$. According to the manufacture's instruction, tablets were handled conventionally. Tumor tissue sections were dewaxed, boiled in microwave antigen retrieval technique for $15 \mathrm{~min}$ to repair antigen, immersed in $3 \% \mathrm{H}_{2} \mathrm{O}_{2}$ for 30 min to block endogenous peroxidase, blocked with $3 \%$ goat serum for $30 \mathrm{~min}$ to block non-specific antigens. The primary antibodies (Table 2) were added to the sections and incubated overnight at $4{ }^{\circ} \mathrm{C}$. After washing, the sections were added to the biotin-labeled goat antirabbit IgG polymer and horseradish enzyme-labeled streptomycin for $30 \mathrm{~min}$ respectively. Positive signals were determined with diaminobenzidine $(\mathrm{DAB})$. The sections were stained with hematoxylin, sealed and analyzed. The results were scored by two pathologists with no knowledge of patient characteristics. The staining intensity was scored as negative $($ score $=0)$, weak $($ score $=1)$, medium $($ score $=2)$, or strong

Table 2 The information of antibodies used for western blot, immunohistochemistry, and flow cytometry

\begin{tabular}{|c|c|c|c|c|}
\hline Antibodies & Reactivity & Dilution & Catalogue & Application \\
\hline GAPDH & Human & $1: 1000$ & Cell Signal Technology, \#5174 & WB \\
\hline PARP1 & Human & $1: 1000$ & Abcam, \#ab191217 & $W B ; I H C$ \\
\hline PD-L1 & Human & $1: 200 ; 2 \mathrm{ug} / \mathrm{ml}$ & Abcam, \#ab205921 & $W B ; I H C$ \\
\hline STING & Human & $1: 1000$ & Cell Signal Technology, \#13,647 & WB \\
\hline p-STING_S366 & Human & $1: 1000$ & Cell Signal Technology, \#50,907 & WB \\
\hline TBK1 & Human & $1: 1000$ & Cell Signal Technology, \#3504 & WB \\
\hline p-TBK1_S172 & Human & $1: 1000$ & Cell Signal Technology, \#5483 & WB \\
\hline IRF3 & Human & $1: 1000$ & Cell Signal Technology, \#11,904 & WB \\
\hline p-IRF3_S396 & Human & $1: 1000$ & Cell Signal Technology, \#29,047 & WB \\
\hline CD8 & Human & $1: 250$ & Abcam, ab93278 & $\mathrm{IHC}$ \\
\hline IFN- $\gamma$ & Human & $1: 50$ & Novus, \#JM10-10 & $\mathrm{IHC}$ \\
\hline CD3 and isotype & Human & $5 \mu \mathrm{l}$ of antibody per test & Elabscience, E-AB-F1001E & Flow cytometry \\
\hline CD4 and isotype & Human & $5 \mu \mathrm{l}$ of antibody per test & Elabscience, E-AB-F1109| & Flow cytometry \\
\hline CD8 and isotype & Human & $5 \mu \mathrm{l}$ of antibody per test & Elabscience, E-AB-F1110D & Flow cytometry \\
\hline PD-L1 and isotype & Human & $5 \mu \mathrm{l}$ of antibody per test & Elabscience, E-AB-F1133E & Flow cytometry \\
\hline IFN- $\gamma$ and isotype & Human & $5 \mu \mathrm{l}$ of antibody per test & Thermo Fisher Scientific, 48-7319-41 & Flow cytometry \\
\hline CD3 and isotype & Mouse & $5 \mu \mathrm{l}$ of antibody per test & Elabscience, E-AB-F1013J & Flow cytometry \\
\hline CD4 and isotype & Mouse & $5 \mu \mathrm{l}$ of antibody per test & Elabscience, E-AB-F1097C & Flow cytometry \\
\hline CD8 and isotype & Mouse & $5 \mu \mathrm{l}$ of antibody per test & Elabscience, E-AB-F1104D & Flow cytometry \\
\hline IFN- $\gamma$ and isotype & Mouse & $5 \mu \mathrm{l}$ of antibody per test & Elabscience, E-AB-F1101E & Flow cytometry \\
\hline
\end{tabular}


$($ score $=3)$. According to the percentage of stainedpositive tumor cells $(0 \%-5 \%, 6 \%-25 \%, 26 \%-50 \%, 51 \%$ $75 \%$, and $76 \%-100 \%$, respectively), the staining extent score was on a scale of $0-4$. By multiplying the staining extent score by the intensity score, a score ranging from 0 to 12 was calculated.

\section{Western-blotting assay}

After the treatment of different PARP inhibitors and Niraparib with concentrations of $0 \mathrm{nM}, 500 \mathrm{nM}$, $1 \mu \mathrm{M}, 5 \mu \mathrm{M}, 10 \mu \mathrm{M}$, and $15 \mu \mathrm{M}$, proteins were collected after cell lysis. Total protein was separated and transferred to polyvinylidene fluoride membranes. Membranes were blocked and incubated with the primary antibody (Table 1 ) at $4{ }^{\circ} \mathrm{C}$ overnight. Samples were washed and incubated with secondary antibody at $37^{\circ} \mathrm{C}$ for $1 \mathrm{~h}$. Bands were detected using a chemiluminescent substrate (Thermo Fisher Scientific Inc. MA, USA) and then developed. The GAPDH band was served at control.

\section{$\mathrm{CD8}^{+} \mathrm{T}$ cell isolation and activation}

Blood samples were collected from healthy donors, an equal volume of PBS was added. Ficoll lymphocyte separation medium (TBD Science, LTS1077, Tianjin, China) was used to isolate the peripheral blood mononuclear cells (PBMCs). After PBMC separation, CD 8 immunomagnetic beads $\left(20 \mu \mathrm{l} / 10^{7}\right.$ cells $)$ purchased from Miltenyi (Germany) were added and incubated at $4{ }^{\circ} \mathrm{C}$ for $15 \mathrm{~min}$. The MS column was prewashed and used to separate $\mathrm{CD} 8^{+} \mathrm{T}$ cells. Before the activation of $\mathrm{T}$ cells, cytokines (Human Recombinant IL-2, Peprotech) $20 \mathrm{ng} / \mathrm{ml}$ were added to ImmunoCult ${ }^{\mathrm{TM}}$-XF T Cell Expansion Medium (Stemcell Technologies, Canada) and mix thoroughly. To activate $\mathrm{T}$ cells, add $25 \mu \mathrm{l} / \mathrm{ml}$ of ImmunoCult ${ }^{\mathrm{TM}}$ Human CD3/CD28 T Cell Activator(Stemcell Technologies, Canada) to the cell suspension. Incubate cells at $37{ }^{\circ} \mathrm{C}$ and $5 \% \mathrm{CO}_{2}$ for up to 3 days. After 3 days of activation, the cells were further cultured 7-10 days for further experiments.

\section{The co-culture assay of tumor cells and $\mathrm{CD}^{+} \mathrm{T}$ cells}

Tumor cells were seeded in a 6-well plate with PBS, Niraparib, PD-L1 blockade, and the combination. Human peripheral blood mononuclear cells were isolated and activated and then cocultured with tumor cells at a 10:1 ratio.

\section{Flow cytometry analysis of PBMCs and cytokines}

Blood samples were collected during treatment with Niraparib. For surface marker staining, $100 \mu \mathrm{l}$ whole blood was stained with FITC-conjugated anti-human
CD3, Percp-Cy5.5-conjugated anti-human CD4, and PE-conjugated anti-human CD8.

For intracellular cytokine staining, whole blood was stimulated with polyclonal cell activation mixture $(2 \mathrm{ul} / \mathrm{ml}$ cell culture) containing the phorbol ester-PMA (Phorbol 12-Myristate 13-Acetate), a calcium ionophore-Ionomycin and the protein transport inhibitor-Brefeldin A (Leukocyte Activation Cocktail, BD, Biosciences, \#550583, San Jose, USA) for 4-6 h. The cells were first stained with surface markers for $30 \mathrm{~min}$. Cells were fixed and permeabilized with BD Cytofix/Cytoperm (BD Bioscience, San Jose, USA) and then washed in FACS buffer (PBS with 5\% FBS). Intracellular staining was performed using APC-conjugated anti-human IFN- $\gamma$.

A total of 80,000 events were collected per sample using flow cytometry (BD Bioscience, San Jose, USA). Flow cytometry data were analyzed using Flowjo software Version 10.0.

\section{Enzyme-linked immunosorbent assay (ELISA)}

Cell culture supernatant with or without Niraparib $(15 \mu \mathrm{M})$ from three times experiment was collected by centrifugation, and cytokine levels were measured according to the instructions of ELISA kits from Multisciences (Hangzhou, Zhejiang, China).

\section{Statistical analysis}

GraphPad Prism software (version 8.0) and SPSS Statistics software (Version 24.0) were used to perform data analysis. Continuous and noncontinuous variables were analyzed by one-way ANOVA, Student's t-test, and chi-square test, separately. The cutoff value of continuous data was calculated by the median. The Kaplan-Meier method with the log-rank test was used to calculate the risk factor related to the overall survival (OS). $P<0.05$ was considered statistically significant.

\section{Results}

PARP inhibitors upregulate PD-L1 expression of ovarian cancer cells in vitro

Increased PD-L1 expression in cancer cells has been shown to enhance PD-L1/PD-1 axis-mediated anticancer immunosuppression. To determine whether PARP inhibitors affect the PD-L1 protein expression, we detected the IC50 of different PARP inhibitors in two cell lines (Fig. 1A, Additional file 1: Figure S1A). Then we treated two types of ovarian cancer cells, SKOV3 and UWB1.289, with two different PARP inhibitors, Olaparib, Niraparib $(10 \mu \mathrm{M})$ for $48 \mathrm{~h}$. Cells treated with PARP inhibitors were collected and western blotting (WB) analysis was performed. 


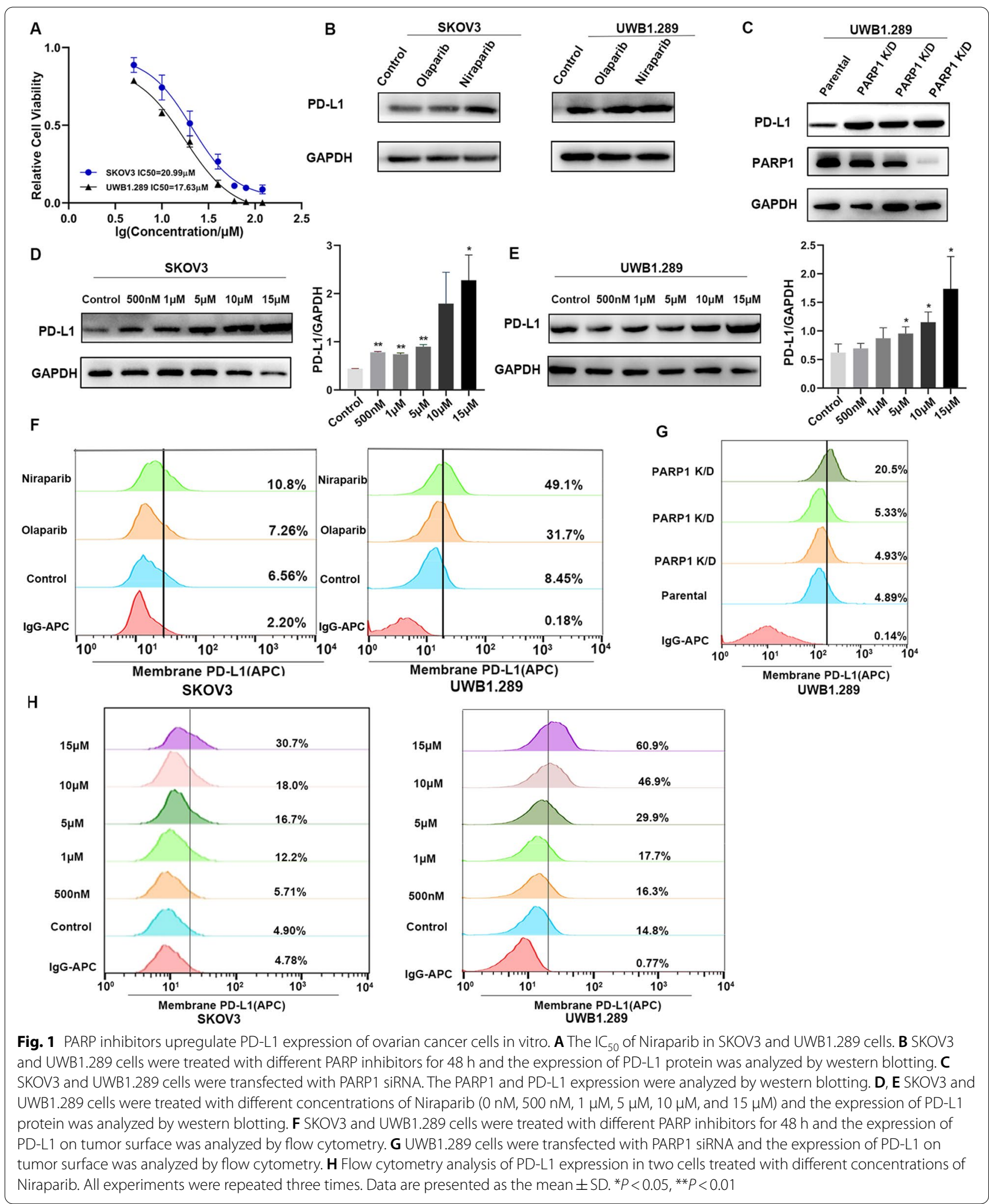


PARP inhibitors upregulated the expression of PD-L1 protein in both cell lines, and Niraparib increased the expression of PD-L1 steadily (Fig. 1B, Additional file 1: Figure S1B). Therefore, we selected Niraparib as a representative agent for following up experiments. To explore whether PD-L1 elevation is specifically due to inhibition of PARP and is not an off-target effect of the inhibitor, we also transfected both cell lines with PARP siRNA and determined the expression of PD-L1 by WB and FACS (Fig. 1C, Additional file 1: Figure S1C, S1D). The results are consistent with the pharmacologic inhibition, and PD-L1 expression was increased in PARP knockdown cells compared with the parental control. Treatment with different concentrations of Niraparib $(0 \mathrm{nM}, 500 \mathrm{nM}$, $1 \mu \mathrm{M}, 5 \mu \mathrm{M}, 10 \mu \mathrm{M}$, and $15 \mu \mathrm{M})$ for $48 \mathrm{~h}$ upregulated PD-L1 expression in SKOV3 and UWB1.289 cells (Fig. 1D, E).

Previous studies showed that PD-L1 expressed on the cancer cell surface could exert immunosuppressive effects by binding to its receptor on activated $\mathrm{T}$ cells. We treated SKOV3 and UWB1.289 cells with different PARP inhibitors, transfected PARP1 siRNA, and treated with different concentrations of Niraparib to explore whether the cell surface PD-L1 levels increased after Niraparib treatment. Cell surface

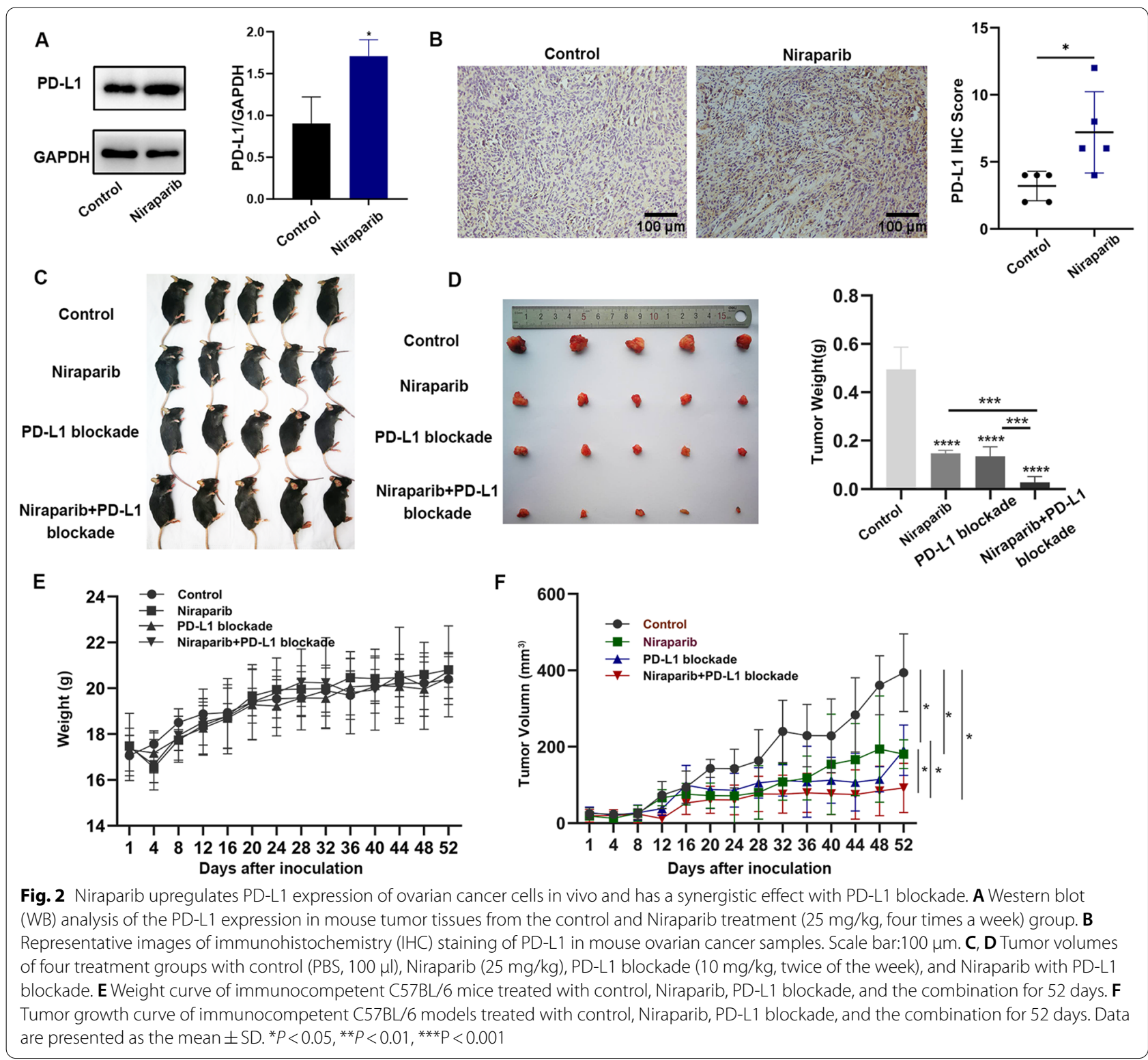


PD-L1 expression increased significantly after PARP inhibitor treatment (Fig. 1F, 1G, 1H, Additional file 1: Figure S1E). Together, these results suggest that PARP inhibitors can increase total and cell surface PD-L1 expression in ovarian cancer cells.

\section{Niraparib upregulates PD-L1 expression of ovarian cancer in vivo and has a synergistic effect with PD-L1 blockade}

The above in vitro experiments indicate that Niraparib increases the expression of PD-L1 in ovarian cancer cells. Next, to explore whether PARP inhibitors could affect PD-L1 expression in mouse models, we inoculated ID8 cells into the right flank of C57BL/6 mice, and after tumors formed, the mice were treated with Niraparib $(25 \mathrm{mg} / \mathrm{kg}$, once a day, four times a week). Tumor tissues of xenografts were isolated and WB analysis was performed. PD-L1 expression was significantly higher in tumors treated with Niraparib than in those from the untreated mice (Fig. 2A). We also assessed PD-L1 expression by IHC staining of tumor tissues from mice. These results are consistent with those in vitro experiments
(Fig. 2B). Therefore, Niraparib could increase PD-L1 expression in ovarian cancer both in vitro and in vivo. Based on these results, we investigated the effect of the combination of the PARP inhibitor Niraparib and PD-L1 blockade in mice (Fig. 2C). While a single agent could inhibit the growth of the tumors, the combination of Niraparib and PD-L1 blockade treatment did hamper tumor growth more effectively than the control treatment (Fig. 2D, F). Besides, there was no significant difference in the body weight curve of mice, indicating the combination of Niraparib and PD-L1 blockade has a little adverse effect (Fig. 2E). These data indicate that, while Niraparib can treat tumors effectively, activation of part of the immune-inhibitory pathway restricts the efficacy of the single agent, which can be overcome by combining with ICBs.

\section{Niraparib treatment alters the proportion and function of immune cells in vivo}

PD-L1 binds with PD-1 and transmits inhibitory signals to the cells, which can induce apoptosis and incapacitation of $\mathrm{CD}^{+} \mathrm{T}$ cells. However, the expression

Table 3 Clinical characteristics between PARP1 low and high expression groups

\begin{tabular}{|c|c|c|c|c|}
\hline Characteristic & Total $(n=72)$ & $\begin{array}{l}\text { PARP1 expression } \\
\text { Low }\end{array}$ & $\begin{array}{l}\text { PARP1 expression } \\
\text { High }\end{array}$ & $P$-value \\
\hline Age (year) & & & & 0.238 \\
\hline$<55$ & $36(50.0)$ & $21(29.2)$ & $15(20.8)$ & \\
\hline$\geq 55$ & $36(50.0)$ & $15(20.8)$ & $21(29.2)$ & \\
\hline FIGO stage (2014) & & & & 0.710 \\
\hline I and || & $8(11.1)$ & $3(4.2)$ & $5(6.9)$ & \\
\hline III and IV & $64(88.9)$ & $33(45.8)$ & $31(43.1)$ & \\
\hline Diameter (cm) & & & & 0.813 \\
\hline$<8$ & $40(55.6)$ & $19(26.4)$ & $21(29.2)$ & \\
\hline$\geq 8$ & $32(44.4)$ & $17(23.6)$ & $15(20.8)$ & \\
\hline Ascitic fluid & & & & 0.312 \\
\hline Yes & $23(31.9)$ & $9(12.5)$ & $14(19.4)$ & \\
\hline NO & $49(68.1)$ & $27(37.5)$ & $22(30.6)$ & \\
\hline CA125 (U/ml) & & & & 0.115 \\
\hline$<35$ & $4(5.6)$ & $0(0.0)$ & $4(5.6)$ & \\
\hline$\geq 35$ & $68(94.4)$ & $36(50.0)$ & $32(44.4)$ & \\
\hline PD-L1 expression & & & & 0.341 \\
\hline Low & $41(56.9)$ & $23(31.9)$ & $18(25.0)$ & \\
\hline High & $31(43.1)$ & $13(18.1)$ & $18(25.0)$ & \\
\hline CD8 expression (cancer tissue) & & & & 0.240 \\
\hline Low & $38(52.8)$ & $17(23.6)$ & $21(29.2)$ & \\
\hline High & $34(47.2)$ & $19(26.4)$ & 15 (20.8) & \\
\hline
\end{tabular}

Values are $\mathrm{n}(\%)$

FIGO, International Federation of Gynecology and Obstetrics; CA125, carbohydrate antigen; PARP1, poly-ADP-ribose polymerase 1; PD-L1, programmed death ligand 1 
and relationship between PD-L1 and CD8 on ovarian cancer is still lacking in sample studies and the correlation of PARP1, PD-L1 and CD8 remains unclear. Seventy-two patients with high-grade serous ovarian cancer were included in the retrospective analysis of our study to determine the relationship between PARP1, PD-L1, and CD8 (Table 3). IHC images showed the different expression of PARP1 in normal ovarian tissues and ovarian cancer tissues (Fig. 3A). The log-rank test and KMplotter analysis showed that ovarian cancer patients with increased PARP1 protein expression had poorer overall five-year survival (Fig. 3B). IHC images showed the expression of PD-L1 and CD8 in normal ovarian tissues and ovarian cancer tissues (Fig. 3C). And the result from GEPIA (Gene Expression Profiling Interactive Analysis) database revealed that PD-L1 had a positive correlation with CD8 (Fig. 3D). However, there was no direct correlation between PARP1, PD-L1, and CD8, considering the limited samples. To better elucidate the impact of Niraparib on immune cells, we collected peripheral blood of three patients receiving Niraparib treatment and compared the levels of $\mathrm{T}$ lymphocytes and cytokines. The clinical characteristics of the three patients were shown in Table 4. The results revealed that the proportion of $\mathrm{CD}_{4}^{+}$and $\mathrm{CD}^{+} \mathrm{T}$ lymphocytes decreased in one of the Niraparib-treated patients, while the proportion of $\mathrm{CD}^{+}, \mathrm{CD}^{+}$, and $\mathrm{CD}^{+} \mathrm{T}$ lymphocytes increased in other two patients and cytokines secreted by $\mathrm{T}$ cells increased in three patients (Fig. 3E-K).

\section{Niraparib treatment enhances the proportion and activation of T lymphocytes in the co-culture system}

The finding that Niraparib can elicit an anti-tumor immune response in patients prompted us to assess changes in immune cells and cytokines in the coculture system. And the morphology of activated $\mathrm{T}$ cells was detected (Fig. 4A). We also determined the sorting efficiency of CD8 $+\mathrm{T}$ cells and the appropriate ratio of effective cells to targeted cells (Fig. 4B, C).
We examined the effect of Niraparib, PD-L1 blockade, and the combination on the activation and function of $\mathrm{T}$ cells in vitro. Activated $\mathrm{CD} 8^{+} \mathrm{T}$ cells isolated from peripheral blood of healthy donors were co-cultured with the UWB1.289 and SKOV3 tumor cells in a 10:1 ratio. We then treated the co-culture system with PBS, Niraparib, PD-L1 blockade and the combination for $48 \mathrm{~h}$. After the co-culture, $\mathrm{T}$ cells were collected and stained with intracellular cytokine markers. The results from the co-culture system showed that the secretion of cytokines in the Niraparib-treated group was increased significantly compared to the control group and the combination enhanced the effect even more than the Niraparib group (Fig. 4D, F). The ELISA results from the co-culture supernatant were consistent with these data (Fig. 4E, G).

\section{Combination of Niraparib with PD-L1 blockade can enhance the proportion and function of T lymphocytes in vivo}

Based on previous observations, we found that Niraparib combined with PD-L1 blockade can hamper growth significantly and increase the proportion and function of $\mathrm{T}$ cells compared to single-drug treatment. To further confirm whether consistent changes were induced in the mouse models, we inoculated ID8 cells into the right flanks of C57BL/6 mice, and after the tumors formed, the mice were divided into the following treatment groups: control (PBS, $100 \mu \mathrm{l}$, intraperitoneal injection), Niraparib (25 $\mathrm{mg} / \mathrm{kg}$, oral administration, four times a week), PD-L1 blockade group $(10 \mathrm{mg} / \mathrm{kg}$, intraperitoneal injection, twice a week), and Niraparib ( $25 \mathrm{mg} / \mathrm{kg}$ ) with PD-L1 blockade group $(10 \mathrm{mg} / \mathrm{kg})$. The mice were sacrificed at 52 days, and the changes in $\mathrm{T}$ cells and cytokine production were assessed in the four groups. Immune profiling by flow cytometry of the peripheral blood of mice showed $\mathrm{CD} 4^{+} \mathrm{T}$ cells and $\mathrm{CD} 8^{+} \mathrm{T}$ cells increased in the Niraparib group and combination group, but there was no significant difference in Niraparib group and combination group (Fig. 5A, B, E). There was a significant increase in the number of $\mathrm{CD} 4^{+} \mathrm{IFN}-\gamma^{+}$cells and

\footnotetext{
(See figure on next page.)

Fig. 3 Niraparib treatment alters the proportion and function of tumor-associated lymphocytes in vivo. A Representative images of immunohistochemistry (IHC) staining for poly ADP-ribose polymerase (PARP1) in human normal ovarian tissues and ovarian cancer samples. Scale bar:100 $\mu \mathrm{m}$. B Expression of PARP1 its relationship with clinical characteristics in ovarian cancer. C Representative images of IHC staining for programmed cell death ligand (PD-L1) and CD8 in human normal ovarian tissues and ovarian cancer samples. Scale bar:100 $\mu \mathrm{m}$. D The correlation of CD8a and PD-L1 in GEPIA database. E-K Flow cytometry analysis of CD3 ${ }^{+} \mathrm{T}$ cells, $\mathrm{CD} 3^{+} \mathrm{CD} 4^{+} \mathrm{T}$ cells, $\mathrm{CD} 3^{+} \mathrm{CD} 8^{+} \mathrm{T}$ cells, $\mathrm{CD} 4^{+} \mathrm{IFN}-\gamma^{+}$cells, and $\mathrm{CD}^{+}{ }^{+} \mathrm{FN}-\gamma^{+}$cells of the Niraparib treatment patients. All experiments were repeated three times. Data are presented as the mean $\pm S D .{ }^{*} P<0.05$, ${ }^{* *} P<0.01$
} 


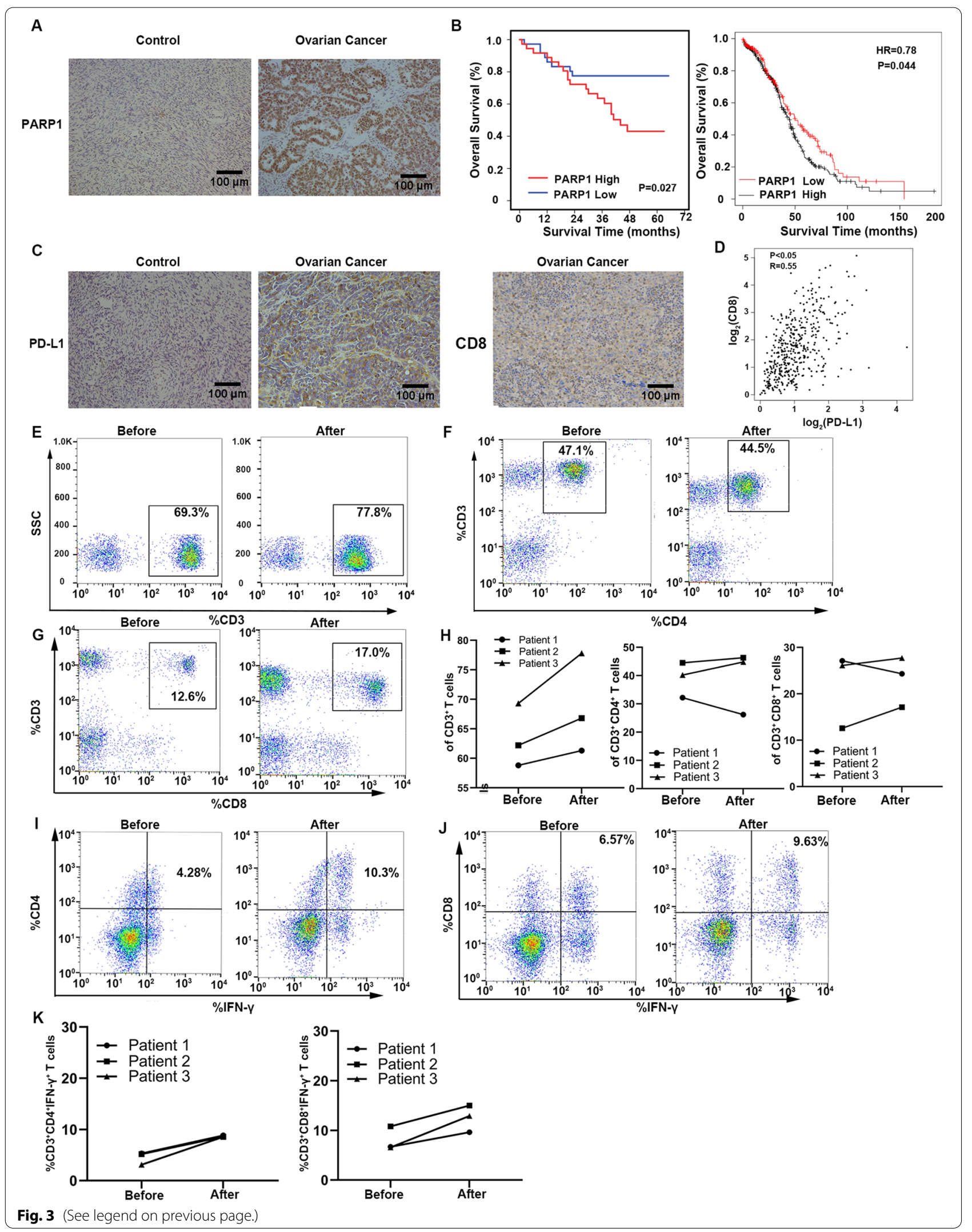


Table 4 The clinical characteristics of three patient with Niraparib treatment

\begin{tabular}{|c|c|c|c|c|c|c|c|c|c|c|}
\hline & Age & Type & $\begin{array}{l}\text { Bilateral } \\
\text { ovaries }\end{array}$ & FIGO & CA125(Before) & CA125(After) & BRCA & $\begin{array}{l}\text { Tumor } \\
\text { metastasis }\end{array}$ & Surgery & Chemotherapy \\
\hline Patient 1 & 45 & HGSC & Yes & $I I I C$ & 6.96 & 7.2 & Wild & No & Yes & Yes \\
\hline Patient 2 & 58 & HGSC & Yes & IV & 13.2 & 12.3 & Wild & No & Yes & Yes \\
\hline Patient 3 & 60 & HGSC & Yes & IV & 7.55 & 11.1 & Wild & No & Yes & Yes \\
\hline
\end{tabular}

CD8 ${ }^{+}$IFN- $\gamma^{+}$cells in the Niraparib and PD-L1 blockade treatment groups, especially in the combination group (Fig. 5C-E).

We next investigated the local immune response upon treatment with Niraparib, PD-L1 blockade and the combination by IHC. Further analysis suggested that Niraparib treatment resulted in an increase of the $\mathrm{CD} 8^{+} \mathrm{T}$ cells, along with the increased production of IFN- $\gamma$, and the combination group enhanced the effect more significantly than the single-agent treatment (Fig. 5F, G). Together, these data indicate that Niraparib elicits an intratumoral immune response, and the combination of Niraparib and PD-L1 blockade seems to work better than the individual treatments.

Thus, in summary, while the PARP inhibitor Niraparib alone can affect the proportion and function of $\mathrm{T}$ cells, the combination of Niraparib and PD-L1 blockade causes remarkable elevation of $\mathrm{CD}^{+}$cytotoxic $\mathrm{T}$ cells and IFN- $\gamma$ compared with the singleagent group.

\section{The mechanism of Niraparib in upregulating the proportion and function of $T$ cells}

Based on the anti-tumor immune response we observed in a previous study, we hypothesized that the PARP inhibitors could induce immune regulation through the activation of the cGAS/STING innate immune pathway. To test whether the pathway was activated by the treatment with Niraparib, we treated the ovarian cancer cells with different concentrations of Niraparib $(0 \mathrm{nM}, 500 \mathrm{nM}, 1 \mu \mathrm{M}, 5 \mu \mathrm{M}, 10 \mu \mathrm{M}$, and $15 \mu \mathrm{M})$. We observed that Niraparib treatment led to the activation of the STING pathway including
p-TBK1-172 and p-IRF3-s396, in both ovarian cell lines (Fig. 6A). And the quantitative figure between the control group and Niraparib treatment $(15 \mu \mathrm{M})$ group was shown (Fig. 6B). We examined the production of IFN- $\beta$, CXCL10, and CCL5 in the supernatants of the control and Niraparib treatment $(15 \mu \mathrm{M})$ group, and the production of IFN- $\beta$, CXCL10, and CCL5 were increased significantly in the Niraparib treatment group, which explained the elevation of PD-L1 expression and the recruitment of $\mathrm{CD}^{+} \mathrm{T}$ lymphocytes (Fig. 6C, D). Besides, we inhibited the activation of the pathway using STING inhibitor (H-151), the PD-L1, CCL5, and CXCL10 were not elevated in the Niraparib treatment group (Fig. 6E, F).

In conclusion, we observed that PARP inhibitorinduced DNA damage activated the STING pathway, which led to the upregulation of PD-L1 and recruitment of $\mathrm{CD} 8^{+} \mathrm{T}$ lymphocytes via the induction of cytokines CXCL10 and CCL5 (Fig. 7). In summary, the PARP inhibitor Niraparib led to the recruitment of $\mathrm{CD}^{+} \mathrm{T}$ cells and exerted an anti-tumor effect in our experiment, and PD-L1 blockade had a synergistic effect with Niraparib.

\section{Discussion}

Ovarian cancer appears to be the most lethal malignancy in the female genital system. Two contributors to this phenomenon are asymptomatic at the early stage and chemotherapy resistance. The prognosis of high-grade ovarian cancer (HGOC) is poor, with a five-year survival of only $47.4 \%[12]$. Therefore, there is an urgent need to find ways to improve the prognosis of patients. In recent years, significant progress has 


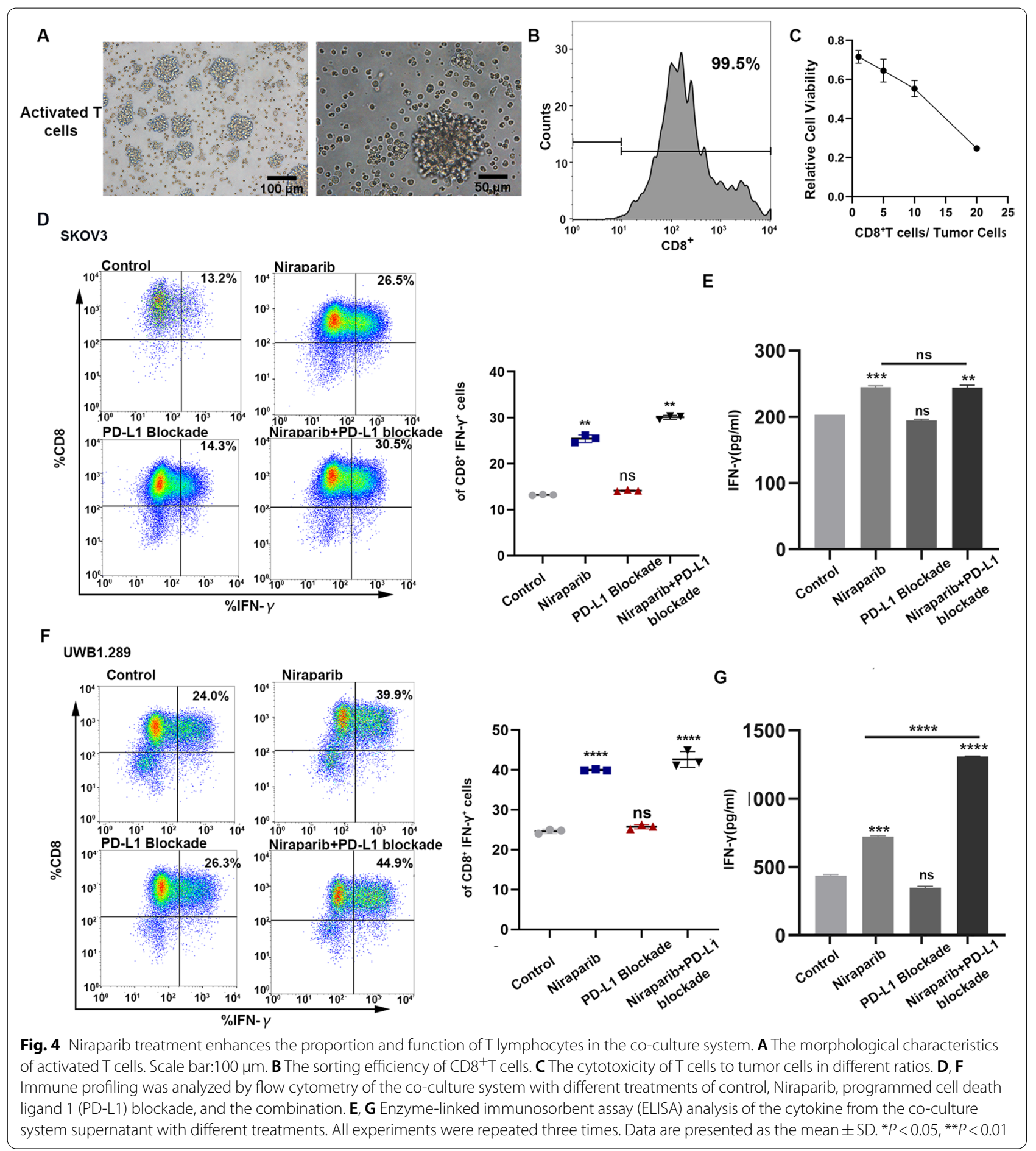

been made in understanding the underlying molecular biology of ovarian cancer and potential targets have been identified. PARP inhibitors and ICBs are both targeted therapeutic strategies under pre-clinical and clinical development for ovarian cancers and have been used in clinical treatment.
In the past several decades, remarkable breakthroughs have been made in exploring tumor immunosuppression. Multiple inhibitory ligands, especially PD-L1, are expressed on the tumor cell surface, which mediates the main cancer immune evasion pathway [13]. PD-L1 binds to its receptor PD-1 expressed on 
$\mathrm{T}$ cells, leading to the suppression of $\mathrm{T}$ cell proliferation and secretion while immune checkpoint inhibitors restore $\mathrm{T}$ cell function [14]. Most success has been achieved with ICBs, such as CTLA-4 and PD-1/ PD-L1 blockade. Ipilimumab, nivolumab, and other immune checkpoint inhibitors have been approved by the FDA to treat multiple types of cancer, such as melanoma, lung, and bladder cancer $[15,16]$. In the past few decades, despite great enthusiasm for immunotherapies, especially antibodies that targeted inhibitory molecules and achieved a significant survival improvement in melanoma and non-small cell lung cancer, few ovarian cancer patients benefited from ICBs (only 15\% with nivolumab and $8 \%$ with the pembrolizumab) [17, 18]. Based on the limited response, current trials started focusing on the combination of ICBs with other targeted therapies, such as PARP inhibitors [19].

Preclinical studies have shown that the combination may have synergistic effects. PARP inhibitors treat tumors with DNA repair defects by inducing synthetic lethality [20]. Also, the cytotoxicity generated by PARP inhibitors can release damaged DNA marking the neoantigen and genomic instability, which would be a pivotal factor in determining tumor immunogenicity [21, 22]. Hence, PARP inhibitor-treated ovarian cancer appears to be more sensitive to ICBs, which may be a potential mechanism for combination therapy.

Only a few researchers have explored the possible tumor microenvironment change after PARP inhibitor treatment. Previous studies showed that Olaparib upregulated PD-L1 expression and impaired the function of T lymphocytes [23, 24]. However, Talazoparib has been shown to drive cytosolic DNA accumulation and STING activation in vitro and mouse models of cancer, leading to increased infiltration by immune cells and enhanced functionality of $\mathrm{CD} 8^{+} \mathrm{T}$ and $\mathrm{NK}$ cells $[25,26]$. The effect of Niraparib on PD-L1 and immune cells has not yet been elucidated. Here, we report a previously unmined role of Niraparib in regulating the anti-tumor immune response in ovarian cancer models. Niraparib enhances the anti-tumor immune response through T-cell-mediated effects. When combined with PD-L1 blockade, Niraparib has a significant anti-tumor effect, suggesting that these combinations may be clinically significant and benefit more patients.

There has been little focus on the mechanism of PARP inhibitors and the immune system. Previous reports have confirmed that DNA damage is associated with the activation of the anti-tumor immune response, including the STING pathway [27, 28]. Upon recognition of pathogenic or self-DNA, the pathway is activated and subsequently produces type I interferons [29]. The constant production of type I IFN initiates the innate immune system and enhances the infiltration of $\mathrm{T}$ lymphocytes and the secretion of cytokines [30, 31].

Previous reports have shown that DNA damage that arises from cytotoxic agents can activate the STING pathway, an innate immune pathway activated by cytoplasmic DNA. Here, we explored the efficacy of PD-L1 blockade combined with Niraparib and investigated the potential mechanism of the combination. We observed that Niraparib led to the activation of the cGAS/STING pathway, thus upregulating IFN$\beta$, which is the direct mechanism of elevated PD-L1 expression. On the other hand, the pathway can activate IRF3 and significantly increase the expression of CCL5 and CXCL10, which leads to T cell recruitment and enhances the function of lymphocytes in ovarian tumors. Our data demonstrated that Niraparib could upregulate PD-L1 expression both in vitro and in vivo. However, the elevation of PD-L1 did not exert a suppressive effect on lymphocytes. Conversely, Niraparib influenced the composition and function of tumorassociated lymphocytes in peripheral blood, which was associated with a good prognosis and played a critical role in the surveillance of ovarian tumor development [32,33]. However, the alteration of immune cells in long-term treatment and whether the changes

\footnotetext{
(See figure on next page.)

Fig. 5 Combination of Niraparib with PD-L1 blockade can enhance the proportion and function of T lymphocytes in vivo. A Flow cytometry analysis of $\mathrm{CD}^{+}{ }^{+} \mathrm{CD} 4^{+} \mathrm{T}$ lymphocytes from the peripheral blood of mice treated with control (PBS, $\left.100 \mu \mathrm{ll}\right)$, Niraparib ( $25 \mathrm{mg} / \mathrm{kg}$, four times a week), PD-L1 blockade (10 mg/kg, twice a week), and the combination. B Flow cytometry analysis of CD3 ${ }^{+} \mathrm{CD} 8^{+} \mathrm{T}$ lymphocytes from the peripheral blood of the mice from the four treatment groups. C Flow cytometry analysis of CD4 IFN- $\gamma^{+} T$ lymphocytes from the peripheral blood of the mice from the four treatment groups. D Flow cytometry analysis of $C D 8^{+} I F N-\gamma^{+} T$ lymphocytes from the peripheral blood of the mice from the four treatment groups. E Quantification of data of lymphocytes with four different treatment groups. F Representative images of immunohistochemistry (IHC) staining for CD8 and IFN- $\gamma$ staining from resected tumors with different treatments at day 52. Scale bar: $50 \mu \mathrm{m}$. G Quantification of lymphocytes and IFN- $\gamma$ with different treatment groups. All experiments were repeated three times. Data are presented as the mean \pm SD. ${ }^{*} P<0.05,{ }^{* *} P<0.01$
} 

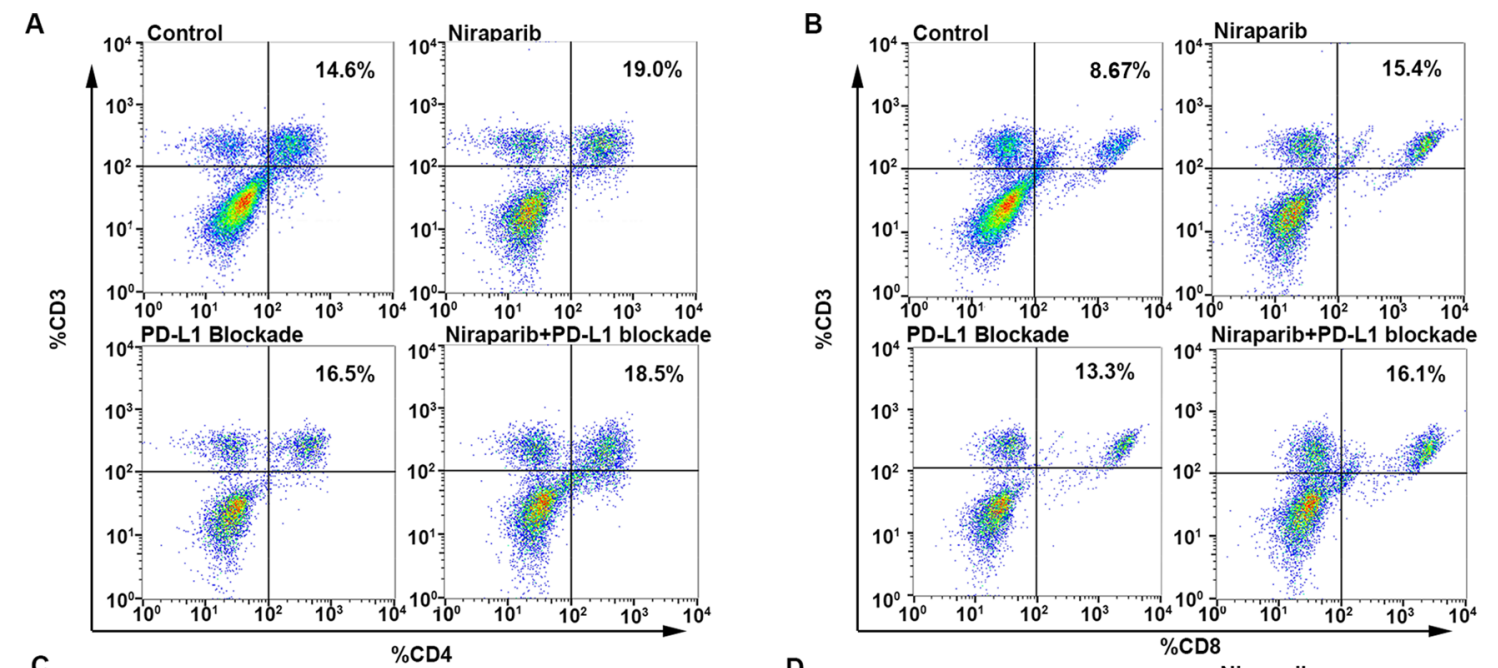

C
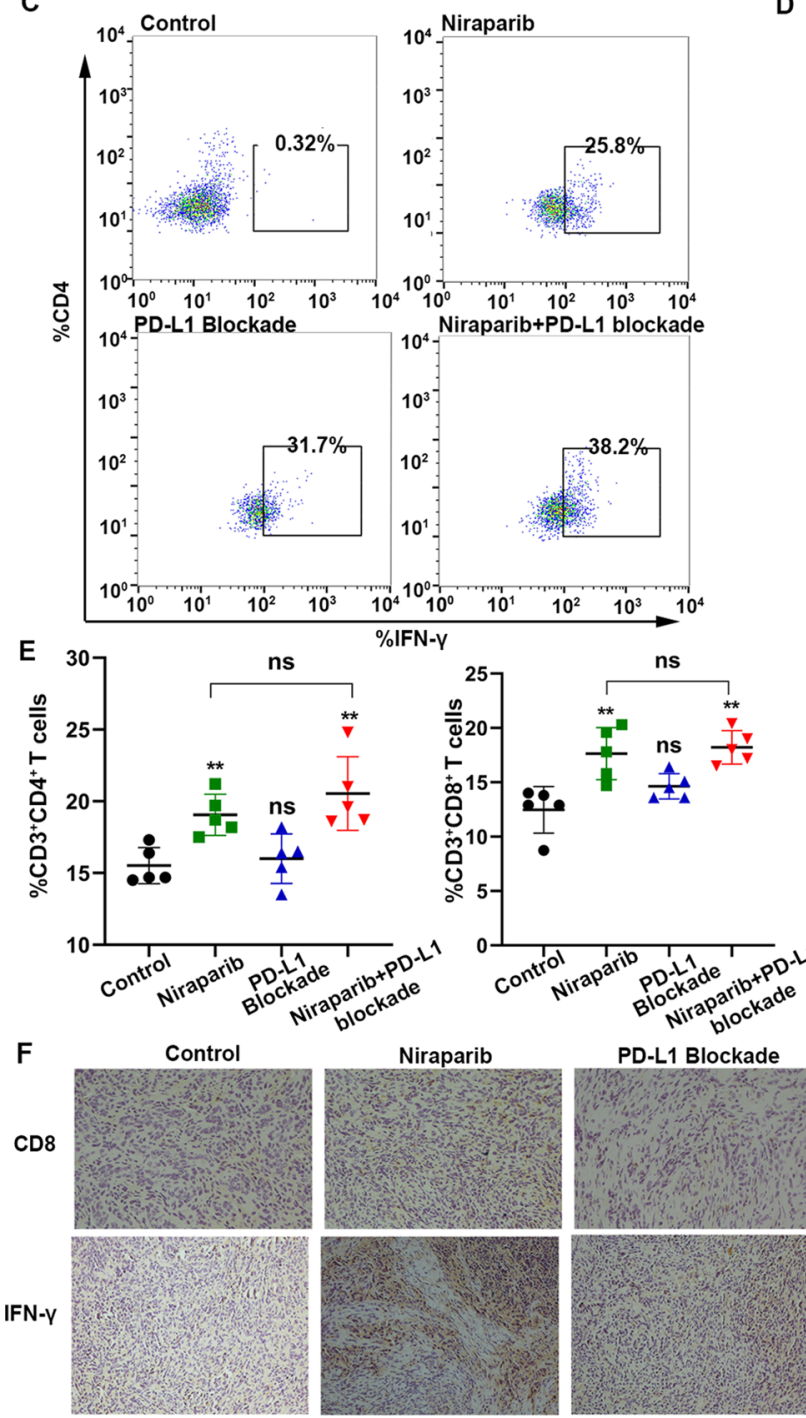

PD-L1 Blockade

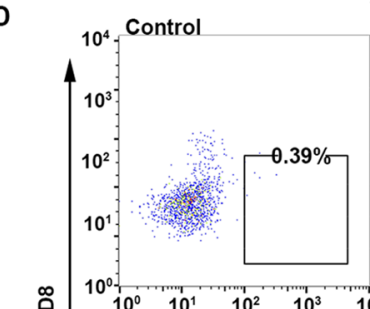

$10^{4}$ Niraparib

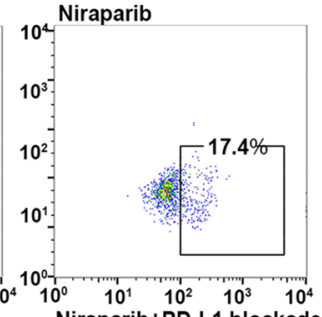

。ำ
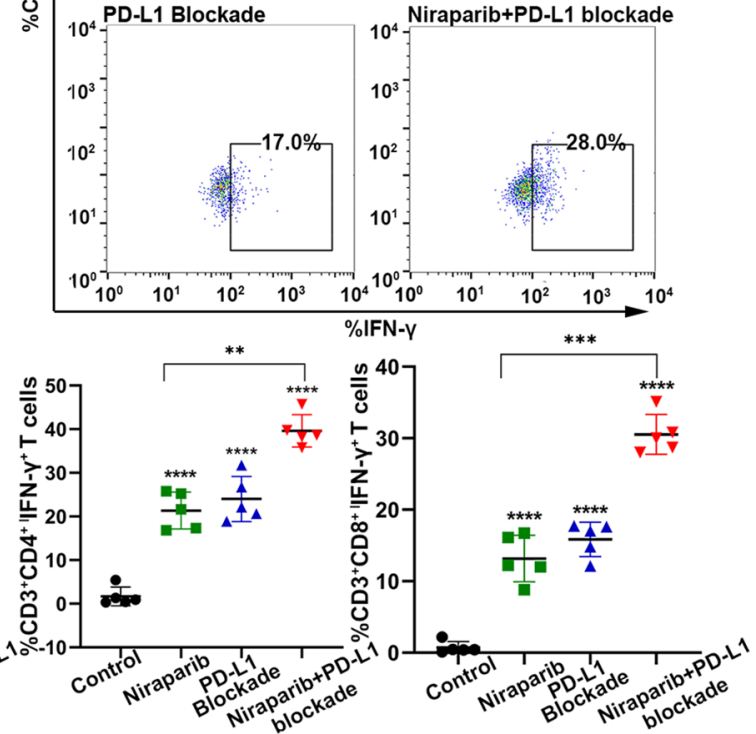

Niraparib+PD-L1 blockade G
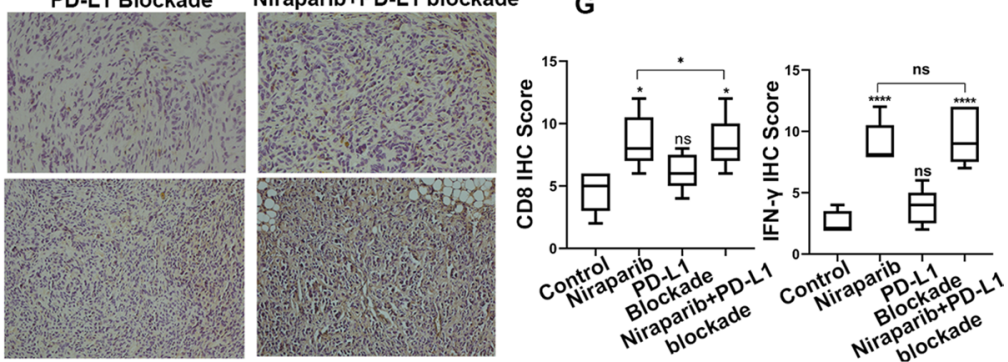

Fig. 5 (See legend on previous page.) 


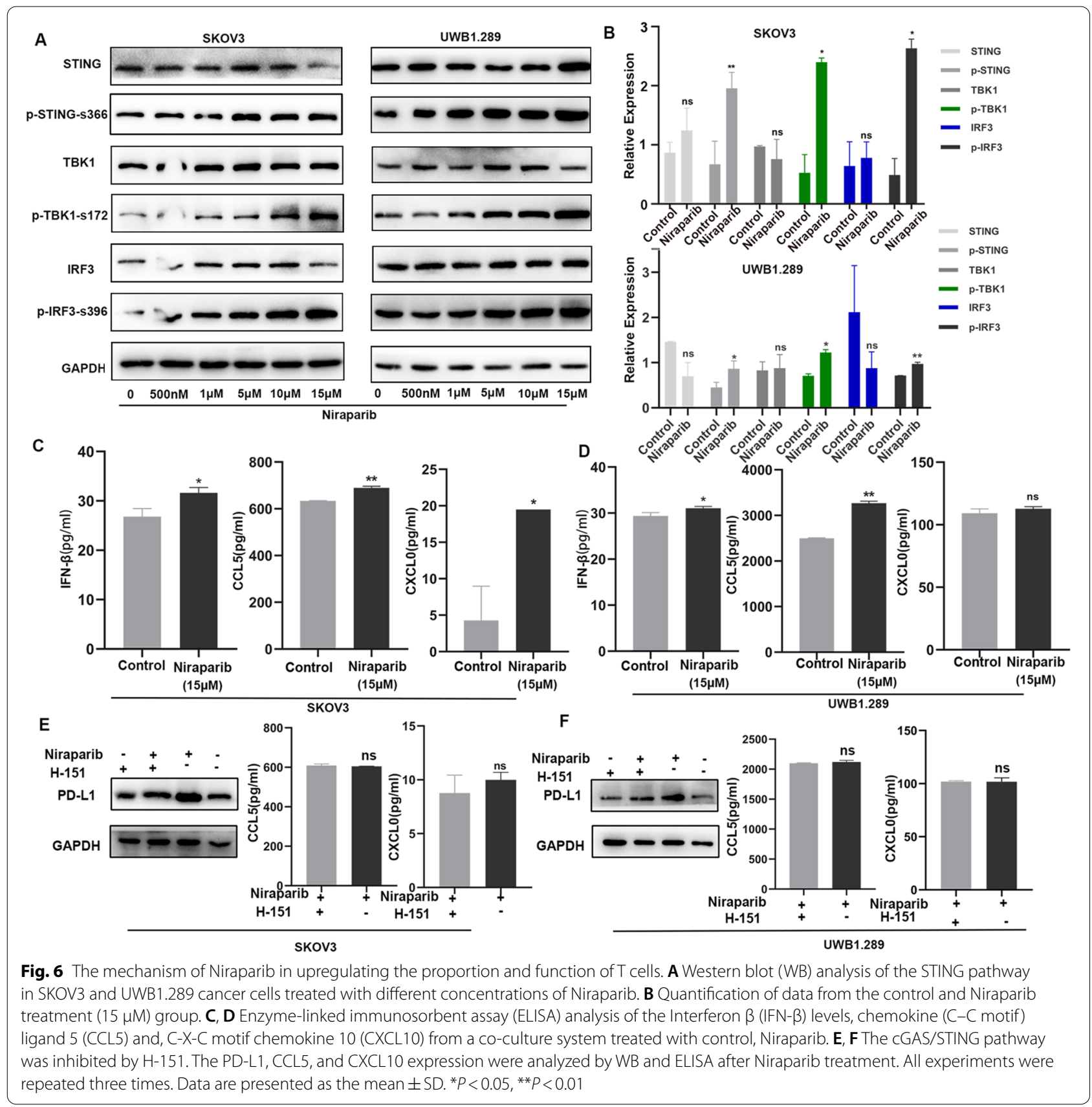

can reflect the response to the treatment is uncertain and needs to be explored in a long-term follow-up.

In conclusion, our study demonstrated the remarkable efficacy of the combination of Niraparib and PD-L1 blockade, which provided a strong scientific rationale for the combination in the clinical settings. Besides, we verified the efficacy of the cGAS/STING pathway in the treatment of Niraparib, and it can be a new target for the treatment of tumors considering the recruitment of $\mathrm{T}$ cells. Further studies will be necessary to explore the effect of targeting the cGAS/ STING pathway in ovarian cancers and the effect of PARP inhibitors or ICBs. 


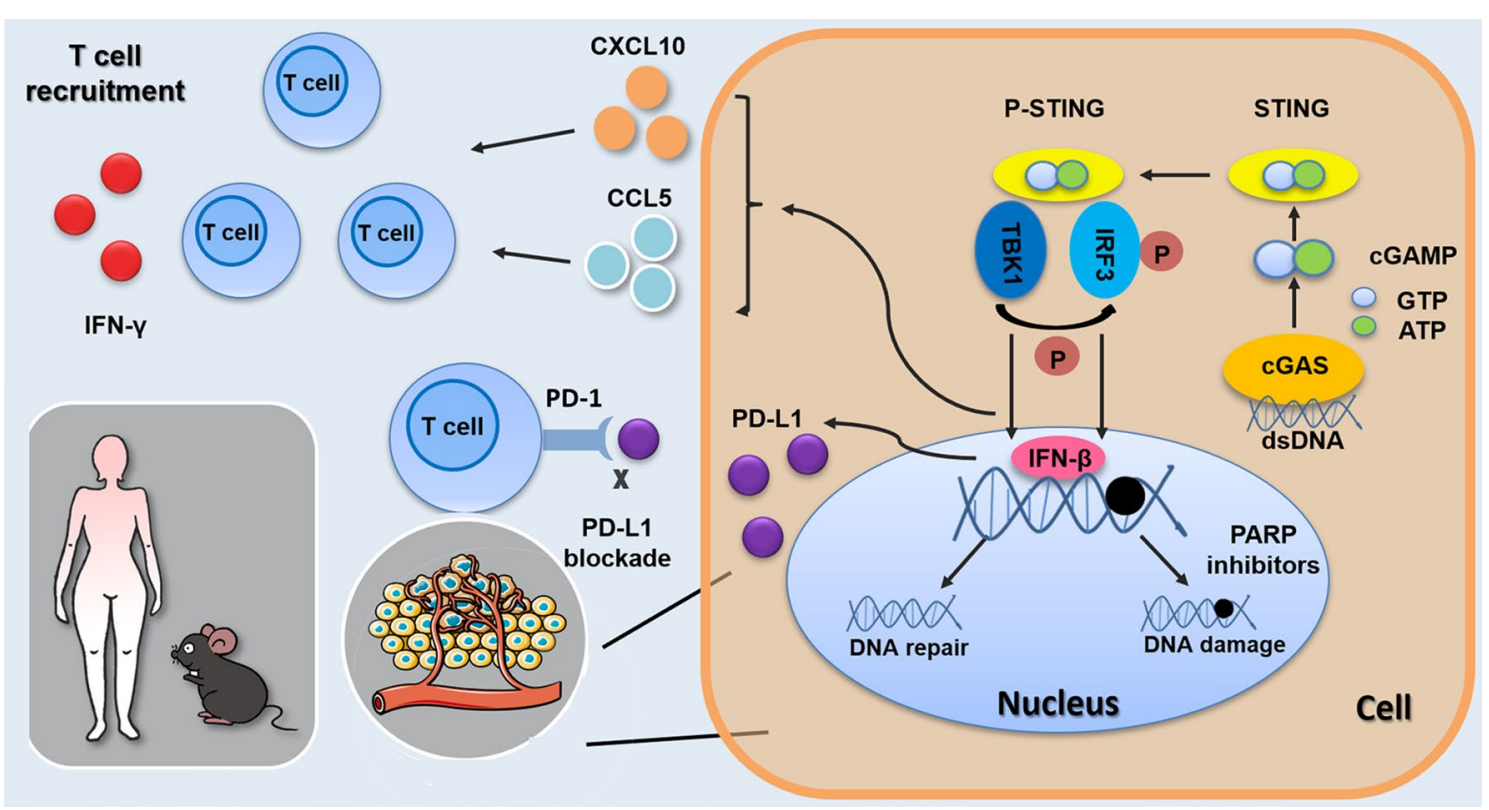

Fig. 7 Model for STING pathway activation in response to PARP inhibitors in ovarian cancer

\section{Abbreviations}

PARP: Poly (ADP) ribose polymerase; PD-L1: Programmed death 1 ligand; FACS: Fluorescence-activated cell sorting; WB: Western blot; IHC: Immunochemistry; cGAS: Cytosolic DNA sensor cyclic GMP-AMP synthetase; STING: Stimulator of interferon genes; TBK1: TANK binding kinase 1; IRF3: Interferon regulatory Factor 3 .

\section{Supplementary Information}

The online version contains supplementary material available at https://doi. org/10.1186/s12967-021-03073-0.

Additional file 1: Figure S1. PARP inhibitors upregulate PD-L1 expression of ovarian cancer cells in vitro. Table S1. Description of clinical data in patients with HGSC.

\section{Acknowledgements}

We sincerely appreciate all participants in the study.

\section{Authors' contributions}

$J M$ performed experiments and analyzed the data; XP, RC conducted statistical analyses; JP designed the study; $J \mathrm{~L}$ and TZ collected the clinical patients' data; $J M$ wrote the manuscript; $Y L, J M$, and $X L$ revised the manuscript. JM and JP were the co-first authors. All authors read and approved the final manuscript.

\section{Funding}

Taishan Scholar Project of Shandong Province (Grant Number tsqn201812130), and the Research Leader Studio of Jinan (Grant Number 2019GXRC049). National Natural Science Foundation of China (Project No. 81602286). The Department of Science Technology of Jinan city (No. 201705051). China Postdoctoral Science Foundation (Project No. 2019T120594) and Shandong natural science united foundation for cancer control (No. ZR2019LZL002).

\section{Availability of data and materials}

The data used and/or analysis during the current study are available from the corresponding author on reasonable request.

\section{Declarations}

Ethics approval and consent to participate

This study was approved by the Ethics Committee of the Qilu Hospital of Shandong University. All participants were recruited after providing signed informed consent.

\section{Consent for publication}

Not available.

\section{Competing interests}

The authors declare no conflict of interests.

\section{Author details}

'Department of Obstetrics and Gynecology, Qilu Hospital, Cheeloo College of Medicine, Shandong University, 107 Wenhua Xi Road, Jinan, Shandong, China. ${ }^{2}$ Gynecology Oncology Key Laboratory, Qilu Hospital, Shandong University, Jinan, Shandong, China. ${ }^{3}$ Department of Obstetrics and Gynecology, University Hospital Aachen (UKA), 52074 Aachen, Germany. ${ }^{4}$ School of Medicine, Cheeloo College of Medicine, Shandong University, Jinan, Shandong, China. ${ }^{5}$ Department of Obstetrics and Gynecology, The Sixth Hospital of Beijing, Beijing, China.

Received: 20 July 2021 Accepted: 7 September 2021

Published online: 07 October 2021

\section{References}

1. Stewart C, Ralyea C, Lockwood S. Ovarian cancer: an integrated review. Semin Oncol Nurs. 2019;35(2):151-6.

2. Henderson JT, Webber EM, Sawaya GF. Screening for ovarian cancer: updated evidence report and systematic review for the US Preventive Services Task Force. JAMA. 2018:319(6):595-606.

3. Matulonis UA, Sood AK, Fallowfield L, Howitt BE, Sehouli J, Karlan BY. Ovarian cancer Nat Rev Dis Primers. 2016:2:16061.

4. Siegel RL, Miller KD, Jemal A. Cancer statistics, 2020. CA Cancer J Clin. 2020:70(1):7-30. 
5. O'Cearbhaill RE. Using PARP inhibitors in advanced ovarian cancer. Oncology (Williston Park). 2018;32(7):339-43.

6. Kaufman B, Shapira-Frommer R, Schmutzler RK, Audeh MW, Friedlander $M$, Balmana J, et al. Olaparib monotherapy in patients with advanced cancer and a germline BRCA1/2 mutation. J Clin Oncol. 2015;33(3):244-50.

7. Mirza MR, Monk BJ, Herrstedt J, Oza AM, Mahner S, Redondo A, et al. Niraparib maintenance therapy in platinum-sensitive, recurrent ovarian cancer. N Engl J Med. 2016;375(22):2154-64.

8. Lord CJ, Ashworth A. Mechanisms of resistance to therapies targeting BRCA-mutant cancers. Nat Med. 2013;19(11):1381-8.

9. Sharma P, Hu-Lieskovan S, Wargo JA, Ribas A. Primary, adaptive, and acquired resistance to cancer immunotherapy. Cell. 2017;168(4):707-23.

10. Rizvi NA, Hellmann MD, Snyder A, Kvistborg P, Makarov V, Havel $\mathrm{JJ}$, et al. Cancer immunology. Mutational landscape determines sensitivity to PD-1 blockade in non-small cell lung cancer. Science. 2015;348(6230):124-8.

11. Domchek SM, Postel-Vinay S, Im SA, Park YH, Delord JP, Italiano A, et al. Olaparib and durvalumab in patients with germline BRCA-mutated metastatic breast cancer (MEDIOLA): an open-label, multicentre, phase 1/2, basket study. Lancet Oncol. 2020;21(9):1155-64.

12. Bray F, Ferlay J, Soerjomataram I, Siegel RL, Torre LA, Jemal A. Global cancer statistics 2018: GLOBOCAN estimates of incidence and mortality worldwide for 36 cancers in 185 countries. CA Cancer J Clin. 2018;68(6):394-424.

13. Dong H, Strome SE, Salomao DR, Tamura H, Hirano F, Flies DB, et al. Tumor-associated B7-H1 promotes T-cell apoptosis: a potential mechanism of immune evasion. Nat Med. 2002:8(8):793-800.

14. Freeman GJ, Long AJ, Iwai Y, Bourque K, Chernova T, Nishimura H, et al. Engagement of the PD-1 immunoinhibitory receptor by a novel B7 family member leads to negative regulation of lymphocyte activation. J Exp Med. 2000;192(7):1027-34.

15. Hodi FS, O'Day SJ, McDermott DF, Weber RW, Sosman JA, Haanen JB, et al. Improved survival with ipilimumab in patients with metastatic melanoma. N Engl J Med. 2010;363(8):711-23.

16. Garon EB, Rizvi NA, Hui R, Leighl N, Balmanoukian AS, Eder JP, et al. Pembrolizumab for the treatment of non-small-cell lung cancer. N Engl J Med. 2015;372(21):2018-28.

17. Hamanishi J, Mandai M, Ikeda T, Minami M, Kawaguchi A, Murayama T, et al. Safety and antitumor activity of anti-PD-1 antibody, nivolumab, in patients with platinum-resistant ovarian cancer. J Clin Oncol. 2015;33(34):4015-22.

18. Matulonis UA, Shapira-Frommer R, Santin AD, Lisyanskaya AS, Pignata $\mathrm{S}$, Vergote I, et al. Antitumor activity and safety of pembrolizumab in patients with advanced recurrent ovarian cancer: results from the phase II KEYNOTE-100 study. Ann Oncol. 2019;30(7):1080-7.

19. Konstantinopoulos PA, Waggoner S, Vidal GA, Mita M, Moroney JW, Holloway R, et al. Single-Arm phases 1 and 2 trial of niraparib in combination with pembrolizumab in patients with recurrent platinum-resistant ovarian carcinoma. JAMA Oncol. 2019;5:1141.

20. Jariyal H, Weinberg F, Achreja A, Nagarath D, Srivastava A. Synthetic lethality: a step forward for personalized medicine in cancer. Drug Discov Today. 2020;25(2):305-20.
21. Chabanon RM, Pedrero M, Lefebvre C, Marabelle A, Soria JC, PostelVinay S. Mutational landscape and sensitivity to immune checkpoint blockers. Clin Cancer Res. 2016;22(17):4309-21.

22. Nebot-Bral L, Brandao D, Verlingue L, Rouleau E, Caron O, Despras E, et al. Hypermutated tumours in the era of immunotherapy: the paradigm of personalised medicine. Eur J Cancer. 2017;84:290-303.

23. Jiao S, Xia W, Yamaguchi H, Wei Y, Chen MK, Hsu JM, et al. PARP Inhibitor upregulates PD-L1 expression and enhances cancer-associated immunosuppression. Clin Cancer Res. 2017;23(14):3711-20.

24. Xue C, Xu Y, Ye W, Xie Q, Gao H, Xu B, et al. Expression of PD-L1 in ovarian cancer and its synergistic antitumor effect with PARP inhibitor. Gynecol Oncol. 2020;157(1):222-33.

25. Huang J, Wang L, Cong Z, Amoozgar Z, Kiner E, Xing D, et al. The PARP1 inhibitor BMN 673 exhibits immunoregulatory effects in a Brca1(-/-) murine model of ovarian cancer. Biochem Biophys Res Commun. 2015;463(4):551-6.

26. Shen J, Zhao W, Ju Z, Wang L, Peng Y, Labrie M, et al. PARPi Triggers the STING-dependent immune response and enhances the therapeutic efficacy of immune checkpoint blockade independent of BRCAness. Cancer Res. 2019;79(2):311-9.

27. Burdette DL, Monroe KM, Sotelo-Troha K, Iwig JS, Eckert B, Hyodo M, et al. STING is a direct innate immune sensor of cyclic di-GMP. Nature. 2011:478(7370):515-8.

28. Ishikawa H, Ma Z, Barber GN. STING regulates intracellular DNAmediated, type I interferon-dependent innate immunity. Nature. 2009;461 (7265):788-92.

29. Li T, Chen ZJ. The cGAS-cGAMP-STING pathway connects DNA damage to inflammation, senescence, and cancer. J Exp Med. 2018;215(5):1287-99.

30. Harlin H, Meng Y, Peterson AC, Zha Y, Tretiakova M, Slingluff C, et al. Chemokine expression in melanoma metastases associated with CD8+ T-cell recruitment. Cancer Res. 2009;69(7):3077-85.

31. Marcus $A$, Mao AJ, Lensink-Vasan M, Wang L, Vance RE, Raulet DH. Tumor-Derived CGAMP Triggers a STING-mediated interferon response in non-tumor cells to activate the NK cell response. Immunity. 2018;49(4):754-63.

32. Sato E, Olson SH, Ahn J, Bundy B, Nishikawa H, Qian F, et al. Intraepithelial CD8+ tumor-infiltrating lymphocytes and a high CD8+/regulatory T cell ratio are associated with favorable prognosis in ovarian cancer. Proc Natl Acad Sci U S A. 2005;102(51):18538-43.

33. Street SE, Cretney E, Smyth MJ. Perforin and interferon-gamma activities independently control tumor initiation, growth, and metastasis. Blood. 2001;97(1):192-7.

\section{Publisher's Note}

Springer Nature remains neutral with regard to jurisdictional claims in published maps and institutional affiliations.

\footnotetext{
Ready to submit your research? Choose BMC and benefit from:

- fast, convenient online submission

- thorough peer review by experienced researchers in your field

- rapid publication on acceptance

- support for research data, including large and complex data types

- gold Open Access which fosters wider collaboration and increased citations

- maximum visibility for your research: over $100 \mathrm{M}$ website views per year
}

At BMC, research is always in progress.

Learn more biomedcentral.com/submissions 